\title{
LOS TALLERES LITERARIOS \\ EN LA FORMACIÓN DE LA LITERATURA DEL FIN DE SIGLO
}

POR

AlejANDRo VARDERI

New York University

\section{ANTECEDENTES}

No es posible entender una zona importante de la literatura que en Venezuela se produce ahora, cuando pareciera que el siglo y, más aun, el milenio, se cierra sobre nosotros, sin remitirnos a la experiencia de los talleres literarios que surgen espontánea e institucionalmente en el país, desde mediados de los años setenta.

Las razones que motivaron la aparición de tales focos de encuentro, especialmente en la capital, tienen mucho que ver con la situación general del panorama literario para aquel entonces, donde la generación del 58, con contadas excepciones, se había asentado, ocupaba los cargos burocráticos del poder cultural, disfrutaba de eternas bolsas de trabajo a expensas del estado, o/y navegaba en las aguas etílicas de los bares ubicados en la populosa zona de Sabana Grande. Esta postura de desencanto y apatía tenía sus raíces en la frustración que, por un lado, muchos autores de izquierdas sentían ante lo inevitable de haberse doblegado al sistema capitalista, que la guerrilla de los años sesenta había intentado destruir, siguiendo el ejemplo de Cuba, y por otro, a su ausencia del panorama internacional -especialmente cuando con el boom la literatura de la periferia latinoamericana había empezado a ser "descubierta" y por ende "redescubierta" en los centros. ${ }^{1}$

Ante un paisaje tan desolador, no es extraño que la literatura venezolana de los sesenta llegase a la nueva generación signada por un desprestigio, no tanto de las obras como de los autores que las habían producido. Este malestar, sólo intuido entonces por los más jóvenes, se encontraba lúcidamente sopesado por ciertos intelectuales que permanecían al margen de las peñas y grupos autocomplacientes, quienes vieron en el taller una posibilidad de canalizar las inquietudes de una generación sin rostro ni ídolos que la identificara.

Sin descontar la importante labor realizada por los talleres a lo largo del país, voy a centrarme aquí en el taller urbano; y concretamente los que se formaron en Caracas desde mediados de los años setenta.

\footnotetext{
${ }^{1}$ Para un análisis pormenorizado del tránsito de la literatura venezolana de los años sesenta a los setenta, remito al estudio de Óscar Rodríguez Ortiz, Intromisión en el paisaje (Caracas: Fundación de Promoción Cultural de Venezuela, 1985) 127.
} 
En 1975 el Centro de Estudios Latinoamericanos "Rómulo Gallegos" (CELARG) por iniciativa de su director Domingo Miliani, Leopoldo Zea —quien desde México había traído la idea-y, especialmente, Oswaldo Trejo, fundan los primeros talleres de la serie. ${ }^{2}$ Talleres en el clásico sentido de la palabra: financiados por el estado y divididos en seis áreas específicas - poesía, narrativa, ensayo, cine, teatro y guiones de radio-a los cuales se accedía por concurso, presentando trabajos previamente producidos. Durante un año, un promedio de diez autores se reunía semanalmente con un coordinador, a fin de leer y discutir textos propios y de escritores invitados. Cada participante recibía una bolsa de trabajo, con la condición de que al finalizar el período entregara un libro que sería publicado en la colección "Voces Nuevas" del CELARG, creada especialmente para tal fin.

En abril del año siguiente otro escritor disidente, Juan Calzadilla, con el apoyo del profesor José Santos Urriola, funda el Taller de Expresión Literaria de la Universidad Simón Bolívar, que pondría en circulación la revista La Gaveta Ilustrada (1977-81). Calzadilla, poeta, pintor y crítico de arte, contaba con una larga experiencia en estas lides, ya que no sólo había animado proyectos semejantes en otras zonas del país, sino que había sido miembro fundador de El Techo de la Ballena: colectivo de artistas y escritores, clave para entender la respuesta de los intelectuales al "clima general de violencia que dominó la vida venezolana entre los años 1960 y $1964{ }^{\prime \prime}{ }^{3}$

A mediados del 77, terminadas las actividades del taller de narrativa del CELARG dirigido por Antonia Palacios, varios de sus integrantes por iniciativa de Alberto Guaura, decidieron seguirse reuniendo, ya desligados del compromiso institucional. Surge así Calicanto, taller coordinado por la misma escritora en su propia casa: "Calicanto" - de ahí el nombre adoptado por el conjunto, cuyo órgano de difusión sería la revista Hojas de Calicanto (1977-83).

Por uno o más de estos tres talleres, surgidos consecutivamente, pasaría la mayor parte de los nuevos autores que hoy contribuyen a dar forma a la literatura del fin de siglo $\mathrm{y}$, por qué no decirlo, constituyen también la generación de relevo en los cargos del poder cultural, las editoriales, los museos, la prensa y el periodismo audiovisual.

\section{LOS TALLERES DEL CELARG}

A más de quince años de haber sido fundados, siguen promoviendo y en especial sirviendo de punto de encuentro para los nuevos autores; si bien adolecen de fallas, producto de la propia estructura sobre la cual se asientan. Su institucionalidad los hace inamovibles e impermeables a los cambios, que no sólo los integrantes sino el país mismo han sufrido en los últimos ocho años: las bolsas de trabajo no se corresponden con la pérdida del valor adquisitivo de la moneda; la colección "Voces Nuevas" ha permanecido paralizada desde hace varios años por falta de recursos, con lo que el trabajo del taller no se difunde; y algunas áreas, como la de guiones de radio, ha debido cerrarse por falta de interés por parte de las emisoras y de quienes en ellas trabajan.

\footnotetext{
${ }^{2}$ La revista Criticarte en su número 10 (Caracas: FUNDARTE, marzo 1986) publicó un recuento del devenir de los talleres literarios y los grupos que de ellos surgieron.

${ }^{3}$ Ángel Rama, Antología del Techo de la Ballena (Caracas: FUNDARTE, 1987) 13.
} 
Ello no significa, sin embargo, que en el pasado hubiesen contribuido realmente a formar escritores. Entre 1975 y 1982, por ejemplo, años del boom tallerístico, el estadio de la formación fue un problema que los talleres no supieron abordar, a raíz de las características del doble comportamiento que signó al conjunto: una fracción considerable de sus integrantes o contaba con experiencia previa en talleres independientes, surgidos espontáneamente a partir de la interrelación entre sus miembros, que les llevó a anteponer la duda ante la dinámica de éstos; o enfrentaban sin interés real este primer contacto, movidos por la posibilidad de disponer durante un año de una beca - como bien lo ilustraba el marcado ausentismo a las reuniones de trabajo, y la negativa de muchos a entregar la obra final al terminarse el período ... Por otra parte, algunos de los directores, más que asumir su función como guías de un taller - cuya mecánica también exige la disección, experimentación, ejercitación del texto y la práctica manual con el lenguaje-condujeron las discusiones sólo a partir de la lectura de trabajos personales de los participantes (en su mayoría anteriores al taller), de escritores invitados y autores varios; ajustando así la experiencia al campo de la docencia que provee información pero no se involucra en el enfrentamiento directo entre el tallerista y la página en blanco.

Formación y experimentación son, entonces, los objetivos que un taller debe perseguir para tener un buen funcionamiento; pues no puede confundirse con una clase de literatura, tampoco con lo que en Estados Unidos se conoce como cursos de creative writing, no. El equilibrio que garantiza el éxito de un taller se logra combinando las dosis precisas de ingenio y afinidad entre los miembros, poder de atracción por parte de quien lo coordina, y consistencia del grupo para reunirse.

Calicanto y La Gaveta Ilustrada, entre 1976 y 1983 aproximadamente, desde mecánicas y con estéticas distintas, cumplieron los propósitos que el trabajo de taller alienta, y constituyen un punto de referencia importante, no sólo para entender los antecedentes de muchos autores de la generación del fin de siglo, sino para hacer un seguimiento, a través de sus revistas, de la actividad literaria que se realizó en el país durante aquellos años.

\section{Calicanto: el taller abierto}

Visto desde afuera, ya que no participé directamente en la experiencia, Calicanto guarda para mí la forma de un imán que atrajo a autores de generaciones y grupos sociales diversos, con ideologías muchas veces opuestas pero que sin embargo compartían una misma pasión por la palabra y, sobre todo, por el intercambio de ideas y la confrontación de puntos de vista - sin descontar una profunda admiración hacia su directora. De hecho, Antonia Palacios territorializó la experiencia: literalmente, al constituirse su casa, y con ella todo lo que el prestigio de la escritora representaba, en la geografía escogida para los encuentros. Y literariamente, pues su estética —centrada en el poder lúdico del lenguaje y la recuperación, a través de la memoria, de un país idealizado - sin imponerse, aglutinó los diversos intereses del taller.

En este sentido Hojas de Calicanto, en su eclecticismo, abrió sus páginas a poesía, prosa, ensayo y entrevistas con autores de múltiples tendencias. Desde la experimentación con el lenguaje en Lourdes Sifontes y Alberto Guaura hasta los textos cargados de humor y anclados en lo cotidiano de Eduardo Liendo, Calicanto demostró que la pluralidad de muchos cuerpos distintos podía tener cabida en un mismo espacio textual y físico. 
Un encuentro de tal naturaleza por un período sostenido de varios años, permite evidentemente que se vayan perfilando afinidades y aparezcan grupos con propuestas mucho más definidas. Fue éste el caso de Tráfico y Guaire quienes, tomando como referencia lo citadino, y reaccionando contra la sensación de "Torre de los panoramas" que iba envolviendo a Calicanto; se decidieron a "dialogar con el país". Ello, elaborando una "poesía de la calle" donde se transplantaba lo conversacional de Roque Dalton y Nicanor Parra, así como el impacto de la metáfora en Gerbasi, Cadenas, Silva Estrada y Crespo al marco urbano.

El surgimiento de estas disidencias es una prueba concreta del éxito del taller abierto, una modalidad que probablemente reaparezca en el futuro, siguiendo el devenir cíclico de tendencias, movimientos y estilos como constante dentro de la modernidad.

\section{La Gaveta Ilustrada: el taller Cerrado}

Si bien el taller literario de la USB no se pretendía cerrado, la misma mecánica del trabajo llevó a que, al año de haberse empezado a reunir, el núcleo quedase constituido. Emilio Briceño Ramos, Juan Calzadilla Arreaza, Gustavo Guerrero, Elvira García, Antonio López Ortega, Julia Marina Müller, Miguel Ángel Piñero, Tomas Richter, y yo mismo, con la coordinación y guía de Juan Calzadilla, laboramos durante dos años, martes y jueves, en las aulas 201 y 202 del Edificio de Matemáticas y Sistemas, y a partir de 1978 en las casas de los integrantes.

La razón por la cual La Gaveta funcionó como taller cerrado se debe en gran medida a las condiciones que motivaron su aparición. Fue creado dentro de una universidad científica y atrajo a estudiantes de los primeros semestres, así que la media de sus integrantes no alcanzaba los veinte años, y la mayoría estudiaba física, química, ingeniería o matemáticas; con lo cual se rompían los esquemas que encasillaban al hecho literario dentro del marco humanístico.

Además, poca o ninguna práctica teníamos en la literatura, lo cual le permitió a Juan Calzadilla poner en funcionamiento sus teorías sobre "la escritura abierta", 4 llevándonos a asumirla como tarea lúdica, de juego y celebración: una fiesta donde, a través de los ejercicios de escritura automática, aprendimos a desinhibirnos, vencer el temor inicial ante la página en blanco, y descubrimos, simultáneamente, el poder poético del lenguaje para trascender la realidad del objeto que nombra, e imbricarse en una red infinita de asociaciones, a fin de producir textos con sentidos diversos que convergerían en un texto único.

Comenzando con las experiencias más sencillas de automatismo psíquico propuestas por los surrealistas, y que comprendían el "cadáver exquisito" y el poema collage, el grupo generó una voz colectiva, múltiple y unívoca simultáneamente. No una pluralidad de cuerpos, cual era el taller abierto, sino un cuerpo plural donde las individualidades se diluían, hasta el punto de hacer imposible reconocer quién había escrito tal o cual fragmento. Ello nos permitió ir ampliando el radio de acción, decir "ángeles" o "paisaje" o "vuelcos" o "suicidio" e inmediatamente escribir cada quien un texto, que al ser leído en alta voz se

\footnotetext{
${ }^{4}$ En este sentido recomiendo la lectura del manifiesto "Hacia una escritura abierta" publicado en $\mathrm{La}$ Gaveta Ilustrada, 1 (Caracas: sin/fecha).
} 
conectaba con los otros hasta generar una historia de sentido único. También apropiarnos, por ejemplo, de las imágenes contenidas en una fotonovela, para inventarle un nuevo diálogo que las transplantara a un contexto mucho más actual y crítico. O desmantelar el poema "Vuelta a la Patria" de José Antonio Pérez Bonalde, recortando todas las palabras del mismo a fin de volverlo a armar bajo el nuevo título, "Patria a la Vuelta".

La culminación de esta técnica se encuentra presente en dos proyectos escritos a ocho manos: Sylvia, novela colectiva, Ritos civicos, ${ }^{5}$ libro fragmentario centrado en lo urbano. Y al llegar a este punto es necesario precisar que la ciudad fue el espacio físico y estético del grupo. No sólo porque todos habíamos nacido en Caracas o vivido allí desde la infancia; sino porque sólo ella en su carácter de corpus colectivo, y por ende anónimo, puede producir incontables encuentros tan intensos como efímeros. Efectivamente: no existía comunión entre nosotros más allá de la que requería el lenguaje. Una vez levantada la sesión de trabajo, cada quien seguía separadamente su camino. Ningún texto mejor entonces para definirnos, que el "rito cívico" donde se consignan las peripecias del señor Gutiérrez a fin de poder cruzar una calle citadina:

Gutiérrez cruza una calle. Sin embargo en la mitad de ésta nota que está atrapado entre dos hileras de carros y que la estrechez del camino le da pocas esperanzas de movilidad. De tal manera que decide caminar a lo largo del sendero de asfalto esperando encontrar algún orificio de salida. A lo lejos divisa una mujer que viene en dirección opuesta. Ambos se encuentran, sin embargo no hay espacio suficiente para cruzar. Gutiérrez le propone, acercando su boca al oído, que él puede muy bien agacharse a ras del suelo y que ella, previo impulso sobre su espalda, avance hacia el lado opuesto. La maniobra, después de varios intentos, parece no resultar. La mujer piensa en subirse a uno de los capós de los carros y abrirle paso a Gutiérrez, pero ésto tampoco resulta. De pronto ambos encuentran la solución en una mirada mutua que se han clavado. Bajo pacto tácito deciden abrazarse; unen sus caras, sus pechos, entrelazan sus piernas ... tratan de girar y cuando ya llevan recorridos 45 grados notan que sus cabezas chocan con la latonería de dos carros paralelos a su posición. En vista de esto, deciden unir sus cabezas al máximo, de forma que encajan sus labios en un sólido beso, logrando así girar los 45 restantes. Agradecidos mutuamente, ya del otro lado, se dan la mano y continúan su travesía a lo largo del sendero (45).

Ese "sólido beso" del lenguaje, tan apasionado como breve, describe en Sylvia el itinerario obsesivo para definir a una mujer, de la cual sólo conocíamos el nombre. Alguien dijo "Sylvia" y todos empezamos a escribir capítulos que después se unirían para darle al texto su forma definitiva. El número VII, por ejemplo:

\section{CAPÍTULO VII}

La avenida comienza a verse poblada por figurillas de carne que el viento conduce a placer en un solo flujo sinuoso de vestimentas y tenues pliegues de piernas o de brazos. Unas y otros se entremezclan, sin que los toque en modo alguno, el parecer de los poseedores a quienes por su parte se les ha escapado ya todo movimiento de miembros y

\footnotetext{
${ }^{5}$ Ritos cívicos (Caracas: La Gaveta, 1980) 112.
} 
de pájaros carbónicos que los rebasa y empuja a cierto punto, acierto destino inmediato del cual ellos pretenden ingenuamente tener certeza; sin advertir la relación que guardan con las aves ahuyentadas a golpes de claxón, con las nubes en descenso de millares de hojas pardas que la arboleda eyacula en medio de su más apacible y secreto susurro.

El viandante pierde la marcha de su cuerpo, el rumbo subterráneo que de alguna manera lo incluye, pese a su voluntad de simple figura que durante la mañana surca el pavimento tan sólo ocupado por su cuerpo. Mientras tanto, el tiempo corre por las avenidas interminables; pareciera perderse detrás del horizonte de torres y de gruas, a no ser que alguna luz roja lo detuviera oportunamente: ¿De qué memoria puede dar prueba el horroroso hociqueo de la lluvia en el cristal sin horizonte de la ventana? ¿El trato que te daban las sábanas mientras yo cuidaba tu sueño del hotel "La Azucena Roja" allí, en la penumbra que el manantial del aire acondicionado empujaba como el ronronco del agua oscura de un dique que contenía tu sueño silenciado por una respiración tan liviana que por ella continuaba hablando un ángel? ¿A qué pueden reducirse estos testimonios apenas conservados - y ni siquiera registrados - por la mirada esquiva del recepcionista dándonos la llave del cuarto 18 , segundo piso, y de los que una miserable factura no consignaba más historia que la anotación clara escueta y prosaica del número y precio de la habitación y el billete escamoteado por los intersticios de la puerta, y la bandeja con el compás de los vasos y la botella de vino, de una marca aun más difusa que la lluvia cómplice, oída detrás de los cristales?

Así, pasó el tiempo de sustituir personajes por personajes, de escribir noche a noche queriendo foliar una memoria a espaldas de mí mismo y saber que a las dos o tres de la mañana cualquiera podía meterse en el cuarto y decirnos: ¿Te acuerdas?

Y yo entendía que ya había de detenerlo todo allí, que el ciclo recomenzaba, que no era más que la suplantación de mis protagonistas. Sin embargo, salía de nuevo a buscar alguna cara de mujer aún a conciencia de que aquello no era sino la fuga emprendida desde el principio, la fuga de las seis de la tarde, la justificación de mis ocho horas de oficina y del entierro de mi nombre en la guía telefónica.

Sylvia, ya no sé si debo atribuirte a la nada o al silencio pero no estoy obligado a olvidar. No sé si me dirijo al aire cuando escribo estas líneas - suponiendo que estás en alguna parte-, que sigues observándome desde la ventana. Casi creo que de tanto fjar la mirada en el papel en blanco he llegado a comprender que la locura no está lejos de los grandes espacios que, persiguiéndote, mi letra no cesa de recorrer. ${ }^{6}$

En verdad resulta difícil descubrir que este capítulo surge combinando fragmentos de seis capítulos escritos separadamente por seis autores diferentes ...

La Gaveta Ilustrada como órgano de difusión del taller, se perfiló estéticamente pues, en torno al trabajo colectivo, que incluyó igualmente proposiciones abiertas del grupo hacia el ambiente cultural local, con objeto de desmitificar ciertos usos y criticar otros. Surgen así Victor Melián Vedia y Collazos Varela: dos autores ficticios a quienes —en el caso de Melián Vedia- se provee de copiosa obra inédita, a fin de dar origen a un escritor que habría pasado desapercibido para la crítica, mientras que a Collazos Varela se le pone a ganar concursos literarios, plagiando textos de autores como Antonio Arráiz y Dionisio Aymará, ello con objeto de condenar la manipulación y el facilismo de tales eventos en el país.

\footnotetext{
${ }^{6}$ La Gaveta Ilustrada, 8 (Caracas: abril, 1979).
} 
De hecho, la mayoría de los integrantes de La Gaveta se negó siempre a participar en concursos, figurar en sus listas de jurados, y ocupar cargos dentro de los organismos culturales. En este sentido, la propuesta grupal superó el marco cerrado del taller para tomar la posición claramente opuesta, tanto a los concursos como a la parcialización de la crítica en general, la burocratización e inercia de las instituciones culturales del estado, y la negativa de muchos sectores a aceptar el carácter lúdico de la escritura como vía para la renovación del lenguaje - tal cual lo consignan los manifiestos publicados en los números $1,5,7$ y 9 de la revista.

Como los primeros talleres del CELARG y Calicanto, La Gaveta debía tener una vida limitada. En su etapa final, Celeste Olalquiaga, quien hoy se ha incorporado con su trabajo ensayístico al discurso crítico internacional en torno a la modernidad, aportó ideas y textos. El año 81 marca el agotamiento definitivo de la propuesta colectiva, y la disolución final del taller. Algunos de sus integrantes seguimos explorando las posibilidades de la ciúdad como tema, asociándonos al Grupo Peligro: colectivo de escritores, arquitectos, fotógrafos, cineastas y artistas visuales que, entre 1982 y 1984, realizó una serie de proyectos centrados en el manejo artístico de la escala urbana.

Pero de aquella experiencia quedan los trece números de la revista, donde también se dió cabida a autores de las más diversas tendencias: Roberto Juarroz, Gonzalo Rojas, Armando Romero, Salvador Garmendia, Esdras Parra, Roberto Echavarren, María Clara Salas y Yolanda Pantin son algunos de los nombres que allí se dieron cita. Además, Ritos cívicos y Cuerpo plural, ${ }^{7}$ antología de textos individuales.

Los frutos de todas estas experiencias con los talleres literarios, como apuntó una vez Oscar Rodríguez Ortiz, no nos pertenecen. Lo único cierto es que marcaron un período y perfilaron una parte de la literatura del fin de siglo, constituyéndose entonces, en un espejo donde, con todos sus aciertos y errores, quienes en ellos participamos no podremos dejar nunca de reconocernos.

\footnotetext{
${ }^{7}$ Cuerpo plural (Caracas: La Gaveta, 1978) 167.
} 
